Creep crack growth of high temperature weldments

First published in:

International Journal of

Pressure Vessels and Piping

Vol. 78 (2001), pp. $795-805$

() 2002 Elsevier Science Ltd, Oxford, United Kingdom.

All rights reserved.

- Reprints -

Authors:

B. Dogan

B. Petrovski 


\title{
Creep Crack Growth of High Temperature Weldments
}

\author{
B.Dogan ${ }^{1}$ and B.Petrovski ${ }^{2}$ \\ ${ }^{1}$ Corresponding Author, GKSS Research Centre, Max-Planck-Str, D-21502 Geesthacht, Germany, \\ Tel.:+49-4152-872563, Fax: +49-4152-872595, e-mail: bilal.dogan@gkss.de \\ ${ }^{2}$ IfW, T.U.Darmstadt, Grafenstr 2, D-64229 Darmstadt, Germany
}

\begin{abstract}
The experimental programme of the EC supported project (SMT 2070) SOTA aimed at addressing a technical and industrial need to provide guidelines for creep crack growth (CCG) testing and data analysis of weldments. Mechanical and creep properties were determined on two pressure vessel steels of P22 (2.25Cr1Mo) and P91 (9Cr1MoVNb). The specimens were taken from pipe welds for weld metal (WM) tests, and simulated heat affected zone (HAZ) material for the HAZ tests.

Creep crack growth (CCG) tests were carried out on cross-weld compact tension (CT) specimens machined out from weldment of pipes. The tests were done at $550{ }^{\circ} \mathrm{C}$ and $600{ }^{\circ} \mathrm{C}$ on $\mathrm{P} 22$ and $\mathrm{P} 91$ materials, respectively. The CT specimens were notched using electrical discharge method (EDM), for a sharp starter crack. This method of initiating sharp starter crack was chosen to make sure that all partners will test specimens with starter crack location as specified in the work programme to study crack initiation and growth in WM, HAZ (both in the centre and type IV region). The CCG tests were carried out following the ASTM E1457-92 [Ref.1]. The partners assessed their data and sent both assessed and their raw data to be further assessed centrally. All the data from partners were analysed and compared with those of partners' own assessed data.

The present paper reports on the analyses of CCG data obtained in the programme including six laboratories from six European countries. The programme addresses the differences and difficulties in testing and the assessment of weldments, and provides guidelines for harmonisation of testing procedures for reliable data production for remanent life assessment of plants with welded components.
\end{abstract}

Keywords: Creep crack growth, $C^{*}(\mathrm{t})$-integral, Data analysis, Defect assessment, Buttwelding, Similar welds, HAZ, P22, P91. 